\begin{tabular}{|c|c|}
\hline & Malaysian Journal of Social Sciences and Humanities (MJSSH) \\
\hline Malaysian Journal of & Volume 5, Issue 12, December 2020 \\
\hline (MJ-sSH) & e-ISSN : 2504-8562 \\
\hline & $\begin{array}{l}\text { Journal home page: } \\
\text { www.msocialsciences.com }\end{array}$ \\
\hline
\end{tabular}

\title{
Hubungan antara Amalan Kemahiran 4C dan Pencapaian Sejarah
}

\author{
M. Kaviza ${ }^{1}$ \\ ${ }_{1}^{1}$ Pusat Pengajian Pendidikan dan Bahasa Moden, Universiti Utara Malaysia (UUM) \\ Correspondence: M. Kaviza (kavizakaviza@yahoo.com)
}

\begin{abstract}
Abstrak
Kajian berbentuk korelasi ini bertujuan untuk menentukan sama ada terdapat hubungan antara amalan kemahiran 4C iaitu kemahiran komunikasi, kemahiran pemikiran kritis, kemahiran kreativiti dan kemahiran kolaborasi dengan pencapaian sejarah. Seramai 60 orang murid Tingkatan Empat yang dipilih berdasarkan teknik persampelan rawak mudah terlibat dalam kajian ini. Instrumen kajian ini merupakan soal selidik dan ujian pencapaian. Data kajian ini dianalisis secara statistik inferensi iaitu ujian Korelasi Pearson dan ujian Regresi Pelbagai melalui perisian IBM SPSS. Dapatan kajian ini menunjukkan bahawa terdapat hubungan linear positif yang sederhana tinggi secara signifikan antara min amalan kemahiran 4C dan pencapaian sejarah. Selain itu, dapatan kajian ini juga telah menunjukkan bahawa terdapat hubungan linear positif yang sederhana tinggi secara signifikan antara min amalan kemahiran komunikasi, kemahiran pemikiran kritis, kemahiran kreativiti dan kemahiran kolaborasi dan pencapaian sejarah. Tambahan pula, amalan kemahiran komunikasi, kemahiran pemikiran kritis, kemahiran kreativiti dan kemahiran kolaborasi dilaporkan merupakan pemboleh ubah peramal dan telah menyumbang sebanyak 22 peratus varians terhadap pencapaian sejarah dalam kajian ini. Implikasi kajian ini telah memaparkan sumber maklumat kepada para guru untuk melaksanakan pengajaran dan pembelajaran sejarah dengan menerapkan amalan kemahiran 4C secara berkesan kerana didapati mempengaruhi peningkatan pencapaian sejarah.
\end{abstract}

Kata kunci: kemahiran 4C, pencapaian sejarah, korelasi

\section{The Correlation between Acquisition of the 4C Skills and History Achievement}

\begin{abstract}
The correlation study aims to determine whether there is relationship between acquisition of the $4 \mathrm{C}$ Skills such as communication, critical thinking, creativity and collaboration skills with history achievement. A total of 60 Form Four student which are selected through on random sampling techniques involved in this study. This research instruments is questionnaire and achievement test. The data of this study were analyzed through inferential statistical such as Pearson Correlation and Multiple Regression test using IBM SPSS software. The finding of this study indicated that there is a significant highly moderate positive linear relationship between mean of acquisition of $4 \mathrm{C}$ skills and history achievement. Beside that, the findings also reported that there is a significant highly moderate positive linear relationship between mean of acquisition of communication, critical thinking, creativity and collaboration skills toward history achievement. In addition, communication, critical thinking, creativity and collaboration skills were reported as predictor variable and contribute 22 percent of variances towards history achievement in this study. The implications of this study have been to
\end{abstract}


provide information for the teachers to inculcate $4 \mathrm{C}$ skills widely and effectively as it has been proven influences the history achievement.

Keywords: 4C skills, history achievement, correlation

\section{Pengenalan}

Anjakan paradigma dalam sistem pendidikan Malaysia melalui Pelan Pembangunan Pendidikan Malaysia 2013-2025 turut membawa perubahan kepada mata pelajaran sejarah pada peringkat nasional sebagai mata pelajaran teras dan wajib lulus dalam peperiksaan Sijil Pelajaran Malaysia (SPM) dan pelaksanaan kurikulum baharu melalui Kurikulum Standard Sekolah Rendah (KSSR) dan Kurikulum Standard Sekolah Menengah (KSSM). Justeru, pelaksanaan pembelajaran abad ke-21 melalui amalan kemahiran 4C iaitu kemahiran komunikasi, kemahiran pemikiran kritis, kemahiran kreativiti dan kemahiran kolaborasi dalam mata pelajaran sejarah berupaya untuk membentuk kemenjadian murid dari aspek pengetahuan, kemahiran dan nilai seperti yang disarankan dalam aspirasi pendidikan negara (Kementerian Pendidikan Malaysia (KPM), 2013; Pusat Perkembangan Kurikulum (PPK), 2018). Sungguhpun begitu, adalah tidak dinafikan bahawa amalan kemahiran 4C yang dapat dibentuk melalui proses pembelajaran abad ke-21 yang telah mula diterapkan sejak tahun 2014 yang bercirikan kepada pendekatan pembelajaran berpusatkan murid adalah mampu dan berupaya dalam memberikan impak positif kepada sikap, minat dan penguasaan prestasi dalam kalangan murid (Mistirine, 2018; Muhamad Maliki, Maimun \& Mohd Aderi, 2018). Namun, terdapat satu keperluan kepada pengkaji untuk meninjau hubungan antara amalan kemahiran 4C dan pencapaian sejarah bagi membolehkan guru-guru merancang aktiviti pengajaran dan pembelajaran sejarah dengan menerapkan amalan kemahiran 4C dengan lebih meluas lagi. Hal ini rentetan daripada dapatan kajian-kajian lepas yang telah melaporkan bahawa amalan kemahiran abad ke-21, kemahiran berfikir aras tinggi (KBAT), soft skills dan written mathematics communication skills, kemahiran terarah kendiri berada pada tahap sederhana dan tinggi dalam pelbagai disiplin ilmu (Choswatun, Riyadi \& Budi, 2019; Nuratiqah \& Muhammad Nor, 2020; Meilanny, Nunung \& Nurliana, 2019; Kaviza, 2020; Arni \& Ruhizan, 2015; Tuan Rahayu, Mohd Aderi \& Mohd Isa, 2017). Maka, tujuan kajian ini adalah untuk mengenal pasti sama ada terdapat hubungan yang signifikan antara amalan kemahiran 4C dan pencapaian sejarah dalam kalangan murid.

\section{Objektif Kajian}

Objektif kajian ini ialah:

i. Mengenal pasti sama ada terdapat hubungan yang signifikan antara amalan kemahiran $4 \mathrm{C}$ dan pencapaian sejarah.

ii. Menentukan sama ada terdapat sumbangan pemboleh ubah peramal iaitu amalan kemahiran kolaborasi, kemahiran pemikiran kritis, kemahiran kreativiti dan kemahiran kolaborasi yang signifikan dengan pencapaian sejarah.

\section{Persoalan Kajian}

Persoalan kajian ini ialah:

i. Adakah terdapat hubungan yang signifikan antara amalan kemahiran 4C dan pencapaian sejarah?

ii. Adakah terdapat sumbangan pemboleh ubah peramal iaitu amalan kemahiran komunikasi, kemahiran pemikiran kritis, kemahiran kreativiti dan kemahiran kolaborasi yang signifikan dengan pencapaian sejarah? 


\section{Hipotesis Kajian}

Hipotesis nul kajian ini ialah:

$\mathrm{H}_{\mathrm{o} 1}$ : Tidak terdapat hubungan yang signifikan antara amalan kemahiran $4 \mathrm{C}$ dan pencapaian sejarah.

$\mathrm{H}_{02}$ : Tidak terdapat sumbangan pemboleh ubah peramal iaitu amalan kemahiran komunikasi, kemahiran pemikiran kritis, kemahiran kreativiti dan kemahiran kolaborasi yang signifikan dengan pencapaian sejarah.

\section{Metod Kajian}

Kajian ini dijalankan secara tinjauan yang menggunakan reka bentuk kajian korelasi (Cresswell, 2014) yang digunakan untuk menentukan hubungan antara dua pemboleh ubah iaitu pemboleh ubah bersandar dan pemboleh ubah tidak bersandar. Seramai 60 orang murid Tingkatan Empat berdasarkan teknik persampelan rawak mudah terlibat dalam kajian ini. Instrumen kajian ini terdiri daripada soal selidik amalan kemahiran 4C dan ujian pencapaian sejarah. Kedua-dua instrumen tersebut telah disahkan oleh pakar-pakar penilai dalam bidang pendidikan sejarah yang berpengalaman serta mempunyai nilai kebolehpercayaan Alfa Cronbach iaitu 0.85 bagi soal selidik dan nilai Kuder Richardson 20 iaitu 0.80 bagi ujian pencapaian sejarah yang dianggap baik dan diterima bagi tujuan kajian ini (Nunnally \& Bernstein, 1994). Tambahan pula, kesemua item-item ujian pencapaian sejarah tersebut juga mempunyai nilai indeks kesukaran dan diskriminasi yang boleh diterima bagi tujuan kajian ini (Nitko \& Brookhart, 2011). Data kuantitatif dalam kajian ini telah dianalisis dengan menggunakan perisian IBM SPSS versi 24 iaitu secara statistik inferensi iaitu ujian korelasi Pearson dan Regresi Pelbagai. Interpretasi kekuatan korelasi dalam kajian ini telah dilakukan berdasarkan interpretasi daripada kajian Davies, (1971) seperti yang ditunjukkan pada Jadual 1.

Jadual 1: Interpretasi Kekuatan Korelasi

\begin{tabular}{cc}
\hline Skor Min & Tahap \\
\hline $0.70-1.00$ & Amat tinggi \\
$0.50-0.69$ & Tinggi \\
$0.30-0.49$ & Sederhana tinggi \\
$0.10-0.29$ & Rendah \\
$0.00-0.09$ & Diabaikan \\
\hline
\end{tabular}

Sumber: Adaptasi daripada Davies, (1971)

\section{Dapatan Kajian}

\section{Adakah terdapat hubungan yang signifikan antara amalan kemahiran 4C dan pencapaian sejarah?}

Berdasarkan Jadual 2, hasil dapatan kajian telah melaporkan bahawa nilai keofisien korelasi Pearson antara min amalan kemahiran $4 \mathrm{C}[r=0.42, p=0.00]$ dan pencapaian sejarah adalah signifikan. Oleh itu, terdapat hubungan linear positif yang sederhana tinggi secara signifikan antara min amalan kemahiran 4C dan pencapaian sejarah. Maka, $\mathrm{H}_{\mathrm{ol}}$ telah berjaya ditolak. Justeru, dapat dirumuskan bahawa terdapat hubungan yang signifikan antara min amalan kemahiran $4 \mathrm{C}$ dan pencapaian sejarah. Perkara ini menerangkan bahawa sekiranya amalan kemahiran 4C meningkat dalam kalangan murid, maka pencapaian sejarah juga akan meningkat secara keseluruhannya.

Jadual 2: Hubungan antara min amalan kemahiran 4C dan pencapaian sejarah

\begin{tabular}{lccc}
\hline & Pencapaian Sejarah & Kekuatan \\
\hline Amalan & Pearson Correlation & $0.42^{* *}$ & Sederhana tinggi \\
\hline
\end{tabular}



DOI: https://doi.org/10.47405/mjssh.v5i12.652

\begin{tabular}{ccc}
\hline Kemahiran 4C & Sig & 0.00 \\
& $\mathrm{~N}$ & 60 \\
** Correlation is significant at the 0.01 level (2-tailed)
\end{tabular}

\section{Adakah terdapat hubungan yang signifikan antara amalan kemahiran komunikasi dan pencapaian sejarah?}

Berdasarkan Jadual 3, hasil dapatan kajian telah melaporkan bahawa nilai keofisien korelasi Pearson antara min amalan kemahiran komunikasi $[r=0.44, p=0.00]$ dan pencapaian sejarah adalah signifikan. Oleh itu, terdapat hubungan linear positif yang sederhana tinggi secara signifikan antara min amalan kemahiran komunikasi dan pencapaian sejarah. Maka, $\mathrm{H}_{\mathrm{ola}}$ telah berjaya ditolak. Justeru, dapat dirumuskan bahawa terdapat hubungan yang signifikan antara min amalan kemahiran komunikasi dan pencapaian sejarah. Perkara ini menerangkan bahawa sekiranya amalan kemahiran komunikasi meningkat dalam kalangan murid, maka pencapaian sejarah juga akan meningkat secara keseluruhannya.

Jadual 3: Hubungan antara min amalan kemahiran komunikasi dan pencapaian sejarah

\begin{tabular}{llcc}
\hline & & Pencapaian Sejarah & Kekuatan \\
\hline Amalan & Pearson Correlation & $0.44^{* *}$ & Sederhana tinggi \\
Kemahiran & Sig & 0.00 & \\
komunikasi & $\mathrm{N}$ & 60 & \\
\hline$* *$ Correlation is & significant at the 0.01 level (2-tailed)
\end{tabular}

\section{Adakah terdapat hubungan yang signifikan antara amalan kemahiran pemikiran kritis dan pencapaian sejarah?}

Berdasarkan Jadual 4, hasil dapatan kajian telah melaporkan bahawa nilai keofisien korelasi Pearson antara min amalan kemahiran pemikiran kritis $[r=0.30, p=0.03]$ dan pencapaian sejarah adalah signifikan. Oleh itu, terdapat hubungan linear positif yang sederhana tinggi secara signifikan antara min amalan kemahiran pemikiran kritis dan pencapaian sejarah. Maka, $\mathrm{H}_{\mathrm{olb}}$ telah berjaya ditolak. Justeru, dapat dirumuskan bahawa terdapat hubungan yang signifikan antara min amalan kemahiran pemikiran kritis dan pencapaian sejarah. Perkara ini menerangkan bahawa sekiranya amalan kemahiran pemikiran kritis meningkat dalam kalangan murid, maka pencapaian sejarah juga akan meningkat secara keseluruhannya.

Jadual 4: Hubungan antara min amalan kemahiran pemikiran kritis dan pencapaian sejarah

\begin{tabular}{llcc}
\hline & & Pencapaian Sejarah & Kekuatan \\
\hline Amalan & Pearson Correlation & $0.30^{* *}$ & Sederhana tinggi \\
Kemahiran & Sig & 0.03 & \\
pemikiran kritis & $\mathrm{N}$ & 60 & \\
** Correlation is significant at the 0.01 level (2-tailed) &
\end{tabular}

\section{Adakah terdapat hubungan yang signifikan antara amalan kemahiran kreativiti dan pencapaian sejarah?}

Berdasarkan Jadual 5, hasil dapatan kajian telah melaporkan bahawa nilai keofisien korelasi Pearson antara min amalan kemahiran kreativiti $[r=0.34, p=0.01]$ dan pencapaian sejarah adalah signifikan. Oleh itu, terdapat hubungan linear positif yang sederhana tinggi secara signifikan antara min amalan kemahiran kreativiti dan pencapaian sejarah. Maka, $\mathrm{H}_{\mathrm{olc}}$ telah berjaya ditolak. Justeru, dapat dirumuskan bahawa terdapat hubungan yang signifikan antara min amalan kemahiran kreativiti dan pencapaian sejarah. Perkara ini menerangkan bahawa sekiranya amalan kemahiran kreativiti meningkat dalam kalangan murid, maka pencapaian sejarah juga akan meningkat secara keseluruhannya. 
DOI: https://doi.org/10.47405/mjssh.v5i12.652

Jadual 5: Hubungan antara min amalan kemahiran kreativiti dan pencapaian sejarah

\begin{tabular}{llcc} 
& & Pencapaian Sejarah & Kekuatan \\
\hline Amalan & Pearson Correlation & $0.34^{* *}$ & Sederhana tinggi \\
Kemahiran & Sig & 0.01 & \\
kreativiti & $\mathrm{N}$ & 60 & \\
\hline
\end{tabular}

** Correlation is significant at the 0.01 level (2-tailed)

\section{Adakah terdapat hubungan yang signifikan antara amalan kemahiran kolaborasi dan pencapaian sejarah?}

Berdasarkan Jadual 6, hasil dapatan kajian telah melaporkan bahawa nilai keofisien korelasi Pearson antara min amalan kemahiran kolaborasi $[r=0.31, p=0.02]$ dan pencapaian sejarah adalah signifikan. Oleh itu, terdapat hubungan linear positif yang sederhana tinggi secara signifikan antara min amalan kemahiran kolaborasi dan pencapaian sejarah. Maka, $\mathrm{H}_{\text {old }}$ telah berjaya ditolak. Justeru, dapat dirumuskan bahawa terdapat hubungan yang signifikan antara min amalan kemahiran kolaborasi dan pencapaian sejarah. Perkara ini menerangkan bahawa sekiranya amalan kemahiran kolaborasi meningkat dalam kalangan murid, maka pencapaian sejarah juga akan meningkat secara keseluruhannya.

Jadual 6: Hubungan antara min amalan kemahiran kolaborasi dan pencapaian sejarah

\begin{tabular}{llcc}
\hline & & Pencapaian Sejarah & Kekuatan \\
\hline Amalan & Pearson Correlation & $0.31^{* *}$ & Sederhana tinggi \\
Kemahiran & Sig & 0.02 & \\
kolaborasi & $\mathrm{N}$ & 60 & \\
\hline$* *$ Correlation is & significant at the 0.01 level (2-tailed)
\end{tabular}

\section{Adakah terdapat sumbangan pembolehubah peramal iaitu amalan kemahiran komunikasi, kemahiran pemikiran kritis, kemahiran kreativiti dan kemahiran kolaborasi yang signifikan dengan pencapaian sejarah?}

Berdasarkan Jadual 7 dan Jadual 8 menunjukkan bahawa pemboleh ubah peramal adalah signifikan dengan pencapaian sejarah $[F(4,55)=3.84, p=0.01]$ dan menyumbang sebanyak 22 peratus varians terhadap pencapaian sejarah $\left(r^{2}=0.22\right)$. Tambahan pula, keempat-empat pemboleh ubah peramal tersebut dilaporkan telah memberi sumbangan secara signifikan dengan pencapaian sejarah berdasarkan nilai pemberat regresi piawai $(\beta)$ iaitu pemboleh ubah kemahiran komunikasi $(\beta=0.35$, $t=2.37, p=0.02)$ yang merupakan penyumbang yang tertinggi dan diikuti dengan pemboleh ubah kemahiran kreativiti $(\beta=0.14, t=0.86, p=0.04)$, pemboleh ubah kemahiran kolaborasi $(\beta=0.07, t=0.47$, $p=0.03)$ dan pemboleh ubah kemahiran pemikiran kritis $(\beta=-0.22, t=-0.13, p=0.01)$. Perkara ini menunjukkan bahawa nilai $(\beta)$ bagi setiap unit peningkatan dalam pemboleh ubah tidak bersandar adalah diikuti dengan peningkatan setiap unit dalam pemboleh ubah bersandar. Oleh itu, nilai pekali menunjukkan bahawa terdapat hubungan linear bagi model persamaan garis lurus bagi pencapaian sejarah dengan pemboleh ubah peramal adalah seperti berikut:

$$
\begin{gathered}
\mathrm{Y}=\mathrm{A}+\mathrm{B}_{1 \mathrm{X} 1}+\mathrm{B}_{2 \mathrm{X} 2}+\mathrm{B}_{2 \mathrm{X} 3}+\mathrm{B}_{2 \mathrm{X} 4}+\mathrm{e} \\
{\left[\mathrm{Y}=-11.02+2.68_{\mathrm{X} 1}+-0.17_{\mathrm{X} 2}+0.67_{\mathrm{X} 3}+0.54_{\mathrm{X} 4}+4.30\right]}
\end{gathered}
$$

di mana

$\mathrm{y}=$ pencapaian sejarah

$\mathrm{A}=$ pemalar

$\mathrm{B}_{1}, \mathrm{~B}_{2}, \mathrm{~B}_{3}, \mathrm{~B}_{4}=$ pekali

$\mathrm{x} 1=$ kemahiran komunikasi

$\mathrm{x}_{2}=$ kemahiran pemikiran kritis

$\mathrm{x}_{3}=$ kemahiran kreativiti

$\mathrm{x} 4=$ kemahiran kolaborasi

$\mathrm{e}=$ ralat kajian 
Maka, $\mathrm{H}_{\mathrm{o} 2}$ telah berjaya ditolak. Justeru, dapat dirumuskan bahawa pemboleh ubah iaitu kemahiran komunikasi, kemahiran pemikiran kritis, kemahiran kreativiti dan kemahiran kolaborasi merupakan pemboleh ubah peramal yang telah menyumbang secara signifikan terhadap pencapaian dalam pembelajaran sejarah iaitu sebanyak 22 peratus varians dalam kajian ini.

Jadual 7: Analisis Varians Regresi Pelbagai

\begin{tabular}{lccccc}
\hline \multicolumn{1}{c}{ Pemboleh ubah } & $\begin{array}{c}\text { Jumlah kuasa } \\
\text { dua }\end{array}$ & $\boldsymbol{d f}$ & $\begin{array}{c}\text { Min kuasa } \\
\text { dua }\end{array}$ & $\boldsymbol{F}$ & Sig. \\
\hline Regresi & 30.35 & 4 & 7.59 & 3.84 & 0.01 \\
Reja & 108.58 & 55 & 1.97 & & \\
Jumlah & 138.93 & 59 & & & \\
\hline
\end{tabular}

Jadual 8: Analisis Regresi Pelbagai Pencapaian Sejarah dengan pemboleh ubah peramal

\begin{tabular}{lccccc}
\hline \multicolumn{1}{c}{ Pemboleh ubah } & $\begin{array}{c}\text { Pekali tidak } \\
\text { piawai }(\mathbf{B})\end{array}$ & Ralat pekali & $\begin{array}{c}\text { Pekali } \\
\text { Piawai }(\boldsymbol{\beta})\end{array}$ & $\boldsymbol{t}$ & Sig. \\
\hline Pemalar & -11.02 & 4.30 & & -2.57 & 0.01 \\
Komunikasi & 2.68 & 1.13 & 0.35 & 2.37 & 0.02 \\
Kritis & -0.17 & 1.31 & -0.22 & -0.13 & 0.01 \\
Kreativiti & 0.67 & 0.78 & 0.14 & 0.86 & 0.04 \\
Kolaborasi & 0.54 & 1.15 & 0.07 & 0.47 & 0.03 \\
\hline
\end{tabular}

\section{Perbincangan Kajian}

Dapatan kajian ini yang menunjukkan bahawa terdapat hubungan linear positif yang sederhana tinggi secara signifikan antara amalan kemahiran 4C iaitu kemahiran komunikasi, kemahiran pemikiran kritis, kemahiran kreativiti dan kemahiran kolaborasi dengan pencapaian sejarah adalah konsisten dengan dapatan kajian Nuratiqah et al. (2020) yang telah melaporkan bahawa terdapat hubungan positif antara tahap penguasaan kemahiran proses sains dan kemahiran abad ke-21 dan dapatan kajian Nurul, Noor Hasimah dan Nur Aida (2015) yang telah melaporkan bahawa terdapat hubungan yang signifikan antara kemahiran abad ke-21 dan persepsi murid serta dapatan kajian Vacide (2019) yang telah menjelaskan tentang kaitan antara pengintegrasian kemahiran 4C dan kemahiran bahasa (reading, writing, listening, speaking) dalam kelas EFL. Sungguhpun begitu, hubungan linear positif yang sederhana tinggi secara signifikan antara kemahiran 4C dan pencapaian sejarah yang dilaporkan dalam kajian ini adalah sealiran dengan dapatan kajian Muhammad Sabri, Nurulhuda dan Ilyani (2020) yang telah menunjukkan bahawa kekerapan dan peratusan kendiri pelajar-pelajar dalam jurusan Pengajian Sarjana Pendidikan Bahasa Arab sebagai bahasa kedua terhadap aplikasi 'konsep 4C' pembelajaran abad ke-21 iaitu kreativiti, pemikiran kritis, kolaborasi dan komunikasi adalah berada pada tahap tinggi dan sederhana dan dapatan kajian Muhammad, Edy dan Yustinus (2019) yang telah menunjukkan bahawa tahap kemahiran komunikasi dan pemikiran kritis berada pada tahap tinggi melalui pelaksanaan model pembelajaran berasaskan masalah serta dapatan kajian YM Raja Abdullah dan Daud (2018) yang melaporkan tahap pengetahuan terhadap amalan konsep 4C adalah tinggi dalam kalangan pelajar di Institut Pendidikan Guru Kampus Dato Razali Ismail yang secara tidak langsung telah menyokong dapatan kajian ini. Hal ini demikian kerana amalan kemahiran 4C dapat melahirkan murid yang mempunyai sifat profil seperti berdaya tahan, mahir berkomunikasi, pemikir, kerja sepasukan, bersifat ingin tahu, berprinsip, bermaklumat, penyayang dan patriotik supaya dapat bersaing pada peringkat global (PPK, 2018). Tambahan pula, amalan kemahiran 4C iaitu kemahiran komunikasi, kemahiran pemikiran kritis, kemahiran kreativiti dan kemahiran kolaborasi yang dilaporkan merupakan pemboleh ubah peramal dan telah menyumbang sebanyak 22 peratus varians terhadap pencapaian sejarah dalam kajian ini adalah sealiran dengan dapatan kajian Kaviza (2019) yang telah membuktikan bahawa kelima-lima konstruk dalam kemahiran pemikiran sejarah iaitu kemahiran memahami kronologi, kemahiran meneroka bukti, kemahiran membuat interpretasi, 
kemahiran membuat imaginasi dan kemahiran membuat rasionalisasi telah menyumbang sebanyak 37 peratus varians terhadap pencapaian sejarah. Hal ini demikian kerana penerapan amalan $4 \mathrm{C}$ dapat merangsang proses pemikiran yang melibatkan penguasaan dan pencapaian dalam aspek pengetahuan, kemahiran dan nilai yang membolehkan murid-murid dapat bersaing pada peringkat antarabangsa. Justeru, dapat dirumuskan bahawa terdapat hubungan antara amalan kemahiran 4C dengan pencapaian sejarah dalam kajian ini.

\section{Kesimpulan}

Kesimpulannya, dapatan kajian ini menunjukkan bahawa terhadap hubungan linear positif yang sederhana tinggi secara signifikan antara amalan kemahiran 4C iaitu kemahiran komunikasi, kemahiran pemikiran kritis, kemahiran kreativiti dan kemahiran kolaborasi dengan pencapaian sejarah. Justeru, implikasi kajian ini telah menyediakan sumber maklumat kepada para guru bahawa amalan kemahiran 4C didapati mempengaruhi peningkatan pencapaian sejarah secara langsung mahupun secara tidak langsung yang telah mencadangkan kepada pengintegrasian amalan kemahiran 4C dengan lebih meluas melalui pelaksanaan pembelajaran abad ke-21 dalam proses pembelajaran dan pemudahcaraan bagi mata pelajaran sejarah.

\section{Rujukan}

Arnie Yuzie Mohd Arshad \& Ruhizan Mohd Yasin. (2015). Kemahiran berfikir aras tinggi murid dalam konteks penyelesaian masalah bagi mata pelajaran sains. Evaluation Studies in Social Science, 4, 81-96.

Choswatun, C., Riyadi \& Budi, U. (2019). Analysis of written mathematical communication skills of elementary school students. Advance in Social Science, Education and Humanities Research, 397, 648-655.

Creswell, J.W. (2014). Educational research: Planning, conducting and evaluating quantitative and qualitative research. ( $4^{\text {th }}$ ed.). United States of America: Pearson New International Edition.

Davies, J.A. (1971). Elementary Survey Analysis. New Jersey: Prentice Hall.

Kaviza, M. (2019). Hubungan penerapan elemen kemahiran pemikiran sejarah dalam proses pengajaran dan pembelajaran terhadap pencapaian mata pelajaran sejarah dalam kalangan murid. Jurnal Kurikulum dan Pengajaran Asia Pasifik, 7(1), 30-38.

Kaviza, M. (2020). Amalan Kemahiran Pembelajaran Terarah Kendiri dalam Mata pelajaran Sejarah: Perspektif murid Tingkatan dua. Malaysian Journal of Social Sciences \& Humanities, 5(1), 109115.

Kementerian Pendidikan Malaysia. (2013). Pelan Pembangunan Pendidikan Malaysia 2013-2025. Putrajaya: Kementerian Pendidikan Malaysia.

Meilanny, B.S, Nunung, N \& Nurliana, C.A. (2019). Soft skills as the strength of milieunial generations in the age of automation and artificial intellingence. Kertas kerja yang dibentangkan di $16^{\text {th }}$ ICLEHI 2019, Singapura.

Mistirine Radin M. Al-Muz-zamil Yasin (2018). Pelaksanaan Pendidikan Abad ke-21 di Malaysia: Satu Tinjauan awal. Sains Humanika, 10(3-2), 1-6.

Mohamad Maliki Ali, maimun Aqsha Lubis \& Mohd Aderi Che Noh. (2018). Keberkesanan pengajaran kurikulum akidah dalam pendidikan Islam berasaskan kemahiran berfikir analitikal di sekolah menengah. ASEAN Comparative Education Research Journal on Islam and Civilization, $2(1), 15-34$.

Muhammad Sabri Shahrir, Nurulhuda Osman \& Ilyani Syiham Muhammad (2020). Aplikasi 'Konsep $4 C^{\prime}$ ' pembelajaran abad ke-21 dalam kalangan guru sarjana mod pengajian pendidikan bahasa Arab cuti sekolah UIAM. e-Jurnal Bahasa dan Linguistik, 2(1), 12-22.

Muhammad, A. R.P., Edy, C \& Yustinus, U.A. (2019). Implementation of problem based learning model to measure communication skills and critical thinking skills of Junior High School Students. Journal of Innovative Science Education, 8(3), 324-331.

Nitko, A.J. \& Brookhart, S.M. (2011). Educational Assessment of students (6 ${ }^{\text {th }}$ ed.). New York: Pearson Ltd. 
Nunnally, J.C., \& Bernstein, I.H. (1994). Psychometric theory ( $3^{\text {rd }}$ ed.). New York: McGraw Hill.

Nuratiqah Aziemah Razali \& Muhammad Nor Syafiq Mohd Sanusi (2020). Analysisi of mastery of Science process skills and $21^{\text {st }}$ century skills among secondary school students. Jurnal Pendidikan Sains dan Matematik Malaysia, 10(1), 16-20.

Nurul Nashrah Salehudin, Noor Hasimah Hassan, Nur Aida Abd Hamid (2015). Matematik dan Kemahiran abad ke-21: Perspektif pelajar. Jurnal Pendidikan Matematik, 3(1), 24-36.

Pusat Perkembangan Kurikulum. (2018). Dokumen Standard kurikulum dan pentaksiran Sejarah tingkatan empat dan lima. Putrajaya: Kementerian Pendidikan Malaysia.

Tuan Rahayu Tuan Lasan, Mohd Aderi Che Noh \& Mohd Isa Hamzah. (2017). Pengetahuan, Sikap dan kesediaan murid terhadap kemahiran berfikir aras tinggi (KBAT) dalam mata pelajaran Tasawwur Islam. Tamu Tinta Artikulasi Membina Ummah, 3(1), 15-28.

Vacide, E. (2019). Integrating 4C skills of $21^{\text {st }}$ century into 4 language skills in EFL classes. International Journal of Education and Research, 7(11), 113-124.

YM Raja Abdullah Raja Ismail \& Daud Ismail (2018). Aplikasi 'Konsep 4C' pembelajaran abad ke-21 dalam kalangan guru pelatih pengajian agama Institut Pendidikan guru kampus Dato' Razali Ismail. Asian People Journal, 1(1), 45-65. 